Proceedings of SALT 29: 22-42, 2019

\title{
When-questions and tense in Inquisitive Semantics*
}

\author{
Jos Tellings \\ Utrecht University
}

\begin{abstract}
Temporal questions with when and their counterparts in other languages display tense restrictions: they are incompatible with the present tense that is interpreted as 'currently ongoing', and English when-questions are incompatible with the present perfect. The existence of tense restrictions is one of the reasons why a theory of the semantics of questions should include an account of tense and aspect. I first propose an explanation of the tense restrictions based on the pragmatics of questions and partial answers. Then, I discuss how tense and aspectual operators can be added to Inquisitive Semantics (Ciardelli, Groenendijk \& Roelofsen 2018).
\end{abstract}

Keywords: temporal questions, when, tense, partial answers, Inquisitive Semantics

\section{Introduction}

Temporal questions are questions that, informally speaking, ask for the duration of an eventuality, its position in time, or about some other temporal property. They can be formed with a wide variety of wh-phrases:

(1) a. When did Mary arrive?

b. How long did you stay in Paris?

c. Until when will I be able to get a reimbursement?

d. At what time does the bus come?

e. During which meeting did Mary kiss John? (Nelken \& Francez 1998)

In this paper I will focus on when-questions and their counterparts in other languages (I write 'WHEN-question' to refer language-independently), although it should

* I thank Bert Le Bruyn, Anja Goldschmidt, Martijn van der Klis, and Henriëtte de Swart for very helpful discussion and feedback, which have improved this paper a lot. In Amsterdam, Floris Roelofsen has been very supportive, and I thank him and the audience at the ILLC Inquisitive Semantics seminar for their valuable input. I am indebted to Chris Barker for pointing me to some very useful literature. I thank the SALT29 audience for their input and questions. All remaining errors are mine. This research is part of the Time in Translation project (http://time-in-translation.hum.uu.nl), funded by NWO grant 360-80-070, which is gratefully acknowledged.

C2019 Tellings 
be noted that the other temporal questions in (1) all have slightly different answerhood conditions that merit their own analysis.

One of the main motivations for studying temporal questions is that they display TENSE RESTRICTIONS. One restriction that will be discussed in this paper is the incompatibility of English when-questions with the present perfect (more discussion of this paradigm, and some exceptions, in section 2.2):

(2) a. When will John read the book? / When did John read the book?

b. *When has John read the book?

This indicates an interaction between the $w h$-word and the temporal meaning of the prejacent, given that there is no general constraint of present perfect in questions (e.g. 'Who has read the book?'). This leads to the general insight that a theory of the meaning of questions should incorporate an account of tense. In fact, one does not need to consider temporal questions in order to reach this conclusion. Consider the following contrast between present perfect and simple past who-questions: ${ }^{1}$

\section{(3) \\ a. Who has read Harry Potter? \\ b. Who read Harry Potter?}

Roughly speaking, (3a) may be used in a context to ask who is familiar with the content of the book, whereas (3b) may for example be asked if your copy of Harry Potter is missing. This contrast is lost in a language like Dutch, since (with eventive predicates as in (3)) it only uses the present perfect to refer to the past events. Thus, tense use in a question plays an important role on how the question may be used.

There is a large literature on the semantics of questions (see Groenendijk \& Stokhof 2011 for an overview; more recently Inquisitive Semantics, Ciardelli et al. 2018). However, this literature mostly focuses on argument questions (who, what), and not on adjunct questions such as the temporal ones in (1). Moreover, these theories have not considered the role of tense and aspect in questions in any detail.

The goals of this paper are twofold: first I will provide data on tense restrictions in WHEN-questions in English and Dutch (\$2), and then propose an account for them based on Barker's (2013) "Answer Ban" constraint on sluices, extended to the domain of temporal questions $(\S 3)$. Second, in order to formalize the concept of 'issues' raised by temporal questions, as used informally in section 3, I will discuss how tense can be added to the framework of Inquisitive Semantics in section 4.

\section{Tense restrictions}

I will discuss two tense restrictions for WHEN-questions in two languages, English and Dutch: one relating to the simple present, and one relating the present perfect.

1 Thanks to Marianne Huijsmans (p.c.) for bringing this contrast to my attention. 


\subsection{Current present tense restriction}

The simple present in English has various readings (e.g. Cowper 1998), but this restriction pertains only to the use of the present that refers to a currently ongoing state (as in 'Mary is tired'). I will refer to this reading as the CURRENT PRESENT. In Dutch, the current present is also available for eventive predicates. In both English and Dutch, WHEN-questions are incompatible with the current present tense:

(4) a. \#When is Mary tired?

b. \#Wanneer is Marie moe?

when is Mary tired

Note that the restriction does not apply to other uses of the simple present, such as a futurate $(5 a)$, or a habitual reading $(5 b)$, brought about here by a quantified answer:

(5) a. When does John speak?

b. When does John sing? Every Saturday evening. [only $\mathrm{OK}$ as a futurate interpretation]

[habitual interpretation]

The current present restriction may be illustrated more clearly with the present progressive, because it normally has a strong 'currently ongoing' interpretation. However, in a WHEN-question a futurate interpretation is forced (similar facts hold for Dutch):

(6) a. Peter is singing. [strongly suggests currently ongoing]

b. When is Peter singing?

[only futurate]

At first sight, the current present restriction may perhaps look like a trivial restriction: you cannot ask when something happens if the same utterance asserts that it takes place 'now'. However, note that the described eventuality could span a longer time interval containing the speech time. A present tense WHEN-question cannot be used to ask about the size of that interval. For example, (7a) does not allow answers with deictic time expressions containing the speech time, such as "this week", etc.

(7) [The SALT conference is going on as we speak, but the speaker doesn't know the start/end dates]

a. \#When is SALT?

b. $\checkmark$ Until when is SALT? / When does SALT end? / ...

I now proceed to the second tense restriction in WHEN-questions. 
When-questions and tense in Inquisitive Semantics

\subsection{Present perfect restriction}

As noted in relation to (2), repeated below, English when-questions are incompatible with the present perfect:
a. When did John read the book?
b. *When has John read the book?

This restriction can be found in some descriptive and teaching grammars of English (e.g. Downing \& Locke 2006: 374), but to my knowledge it has not been analyzed in the formal linguistic literature (Klein 1992 mentions the restriction briefly (p. 526 and 547n), but does not analyze it further).

In Dutch, however, present perfect WHEN-questions are completely natural (in fact, they are typically preferred over simple past WHEN-questions):

(9) Wanneer heb je dat boek gelezen? when have you that book read?

'When did you read that book?'

The contrast of (8b) vs. (9) is the basic contrast, but there are two exceptions to the English pattern. First, English when-questions can have the present perfect when they are non-temporal questions. This is the case for negatively biased questions with since when (10), and for questions with the NPI ever (11):

(10) a. Since when has Turkey been part of Europe?

b. Since when have you been the quitting type?
[Europarl corpus] $^{2}$

[iWeb corpus]

(11) a. When have we ever seen Hamas investigate its own actions? [Europarl]

b. When have we ever needed an excuse to grab a gin \& tonic? [iWeb]

The constructions in (10) are known in the literature as since when-attacks or metaconversational since when-questions (Kiss 2017, and references there). There seems to be variation with respect to the possibility of having a non-biased interpretation of (10), i.e. allowing $(10 a, b)$ as sincere information-seeking questions: some native speakers I polled allowed it, others did not (and prefer 'how long'). Note that intonation and aspectual class also influence the availability of a (non-)biased interpretation, but I will have no further analysis of since when questions in this paper.

As for (11), it has been noted before that wh-questions with NPI ever can have rhetorical interpretations (Han \& Siegel 1997; van Rooy 2003).

2 Examples obtained from the Europarl corpus (Koehn 2005) and the iWeb corpus (https://corpus.byu. edu) are indicated as such at the end of the line. 


\begin{tabular}{l|c|c|}
\hline & English & Dutch \\
\hline current present tense & \multicolumn{1}{|c}{$\begin{array}{c}\boldsymbol{X} \\
(\checkmark \text { under future/habitual readings of the present })\end{array}$} \\
\hline present perfect & $\begin{array}{c}\boldsymbol{X} \\
(\checkmark \text { in rhetorical questions } \\
\text { and iterative readings })\end{array}$ & \\
\hline
\end{tabular}

Table 1 Tense restrictions in WHEN-questions

The second exception is that English present perfect when-questions improve under existential readings that ask about multiple events or times:

(12) When have you been in America?

a. \#Last month.

[single time answer]

b. $\checkmark$ In 2003, 2004, 2006, and 2009.

[multiple times answer]

Example (13) is a corpus example that likewise suggests multiple earlier times:

(13) [Think about the passive-aggressive person in your life, and notice how you feel as you think about them and what they do. [...]]

When else have you felt the same feeling you're feeling now?

The empirical picture is summarized in Table 1.

Finally, I note that the observation about multiple-time answers is supported by similar judgments in Swedish, a language that in the relevant tense-related matters is quite similar to English (e.g. the present perfect puzzle; Rothstein 2008). ${ }^{3}$

\section{Explaining tense restrictions}

Before I proceed to my account of the tense restrictions described above, it will be useful to have a better idea of how temporal questions are used. A more formal notion of the meaning of temporal questions will be given in section 4 , but for

3 For example, the present perfect WHEN-question in (i.a) implies multiple years, whereas the simple past one in (i.b) does not:

(i) a. När har Beatles spelat i Stockholm? [perfect] when have the Beatles played in Stockholm

$\begin{array}{lll}\text { b. När spelade Beatles i Stockholm? } & \text { [past] } \\ \text { when played the Beatles in Stockholm } & \end{array}$ when played the Beatles in Stockholm

Thanks to Jesper Carlson (p.c.) and Josefin Lindgren (p.c.) for judgments. 
now it will suffice to make a few pre-theoretical observations about the answerhood conditions of WHEN-questions. A question like (8a) can for example be answered with a calendrical expression ('in January'), or with an event description ('during his holiday in France'). This has led to some debate on whether temporal questions ask for events, or for intervals (Nelken \& Francez 1998: 17). I will simply assume that WHEN-questions ask for time intervals, and that it is possible to go from eventualities to intervals and back by means of a temporal trace function.

The tense and aspectual properties of the prejacent further determine what kind of time interval is asked for. In a perfective past question such as (8a) a felicitous answer must provide an interval that contains the running time of the event (the reading of the book in (8a); following Nelken \& Francez 1998). But now consider a scenario in which A and B spotted John a while ago as he was reading a book. Then there is a preference for past progressive tense in the question, and an answer can be given that specifies a timepoint within the running time of the event:

(14) A: When was John reading that book (again)?

B: Yesterday at 8am.

Thus, with formal details to be filled in in section 4, I assume that a WHEN-question raises an issue about the running time of the event described in the prejacent.

\subsection{The Answer Ban for temporal questions}

My account for the tense restrictions in WHEN-questions starts with a seemingly unrelated set of data, namely that of PARTIALLY RESOLVED questions. Consider the scenario in which a question asks for a plurality of individuals, but has been resolved for a subpart of that plurality:

(15) [it is common ground that Linda invited three people for dinner]

a. A: Linda invited Peter.

b. \#B: Who did Linda invite?

c. B: Who else did Linda invite? / Other than Peter, who did Linda invite?

Here B cannot use (15b) to inquire about the remaining two invitees. The partial knowledge provided in (15a) must be explicitly flagged as in (15c), for example by the additive particle else, the word other, or by some more elaborate construction. The function of else is twofold: it introduces an additive presupposition, and it restricts the domain of the question ('witness removal'; Harris 2014, Theiler 2018). A 
similar example is in (16), in which the partially established answer is not explicitly mentioned, but partiality is clear from the context. ${ }^{4}$

(16) [I cooked a three-course dinner. We've just had the starter, which was soup.]

a. \#What did you cook?

b. What else did you cook? / In addition to the soup, what did you cook?

We may refer to these cases as PARTIALITY-BY-PLURALITY. It exists in the temporal domain, too, as the following corpus example (fragment of an interview) shows: ${ }^{5}$

(17) [Host: The arc of the moral universe quote is one that Dr. King used many times, including during the march from Selma in 1965. [...]]

Host: Professor Carson, when else did Dr. King talk about the arc of the moral universe?

[iWeb]

I argue that the infelicity of asking questions that have been partially settled is related to a constraint proposed by Barker (2013) in the domain of sluices. ${ }^{6}$ Cases like (18) show an obligatory use of else, reminiscent of (15/16):

(18) John left, but I don't know who \#(else).

(Barker 2013: 216)

The Answer Ban

(Barker 2013: 216)

The antecedent clause [of a sluice, JT] must not resolve, or even partially resolve, the issue raised by the sluiced interrogative.

4 Note that, depending on the contextual circumstances, there may be implicit quantifier domain restriction, so that (16a) is understood as "What did you cook for the main course?".

5 Most when else questions are biased (and come with present tense), as in (i). However, other examples like (17) are found in corpora.

(i) When else do you get to have more than one dessert?

$\rightsquigarrow$ you rarely get to have more than one dessert

6 One may alternatively believe that this is a sort of weakened version of a default pragmatic assumption on asking questions, viz. SPEAKER IGNORANCE (e.g. Ginzburg 1992: §1.4.1): a speaker should ask a question that she does not know the answer to. It has been noted that in various contexts speaker ignorance does not hold, e.g. in exam questions. However, an exam context does not rescue a partially settled question:

(i) Examiner: Columbus sailed four times to the Americas. The first voyage was in 1492. \#When did Columbus sail to the Americas? 
The Answer Ban rules out the version of (18) without else: the issue raised by the sluiced interrogative is 'Who left?', but this has been partially resolved by the antecedent clause 'John left'.

I argue that the Answer Ban is not just in play in cases of sluicing, but more generally in plain questions such as (15-17). That the Answer Ban is a more general constraint on questions has been observed before by Kroll (2016: 726n). ${ }^{7}$ To illustrate for the temporal question (17), recall that I assumed (beginning of section 3 ) that WHEN-questions raise an issue about the running time of an event. The previous sentence in (17) partially resolves this issue by establishing that one instance of the event took place during the march from Selma. This instantiates (the general version of) the Answer Ban and thus requires some periphrasis, e.g. with else.

Apart from subparts of plural answers, there is a second way in which partiality can manifest itself: PARTIALITY-BY-DESCRIPTION. This happens when a singular answer is partially described. This is a little hard to illustrate for plain who-questions, because a question such as 'Who did Ed meet?' can be interpreted either as raising an issue about the sort of person he met ('a poet'), or more specifically about the identity of the person he met (see more discussion of this point in Barker 2013: 216). However, partiality by description will turn out to be important for temporal questions and explaining tense restrictions, to which I now turn.

\subsection{Current present restriction}

I will start with an account for the current present tense restriction. I claim that WHEN-questions count as partially resolved by description when a point in the in-

7 Space limits prevent me from elaborating on the derivation of the Answer Ban from more general constraints in the grammar. In earlier work it has been related to Maximize Presupposition (Kroll 2016), to inquisitive entailment (Barros 2013, 2014), and to conditions on ellipsis and givenness (Barker 2013: §6.4). I would like to suggest that else in sluices and questions is an obligatory presupposition trigger, similar to items such as too and again (see Bade 2016 and references there). Compare the following triples consisting of: the standard examples from the obligatory presupposition trigger literature in (a), Barker's sluices in (b), and my root questions in (c):

(i) a. John lives in France. Mary lives in France \#(too).

b. John lives in France, but I don't know who \#(else).

c. John lives in France. Who \#(else) lives in France?

(ii) a. John went to France last year. He went to France this year \#(again).

b. John went to France last year, but I don't know when \#(else).

c. John went to France last year. When \#(else) did he go to France?

How this relates to the Maximize Presupposition vs. Obligatory Implicatures accounts of obligatory triggers (terminology as in Bade 2016), I leave for later work. 
terval they ask for has been established in the context. This can be illustrated for other tenses than the current present, for example the simple past:

(20) [John was sick for some time, but is better now.]

A: I know that John was sick on November 10th, because he didn't come to work that day.

\#B: When was John sick?

$\mathrm{B}^{\prime}$ : Until when was John sick?

B cannot use the when-question if she is interested in the full time interval of the state of John's illness. Instead, just like in the previous cases (15-17), a more specific question must be asked, such as 'until when'. Example (7) above makes a similar point about the present tense.

The crucial difference between the current present tense and cases such as (20) is the following. Whereas in (20) a temporal adverbial like 'on November 10th' is needed to specify a timepoint inside the running time interval (and thus invoking partiality-by-description), I argue that the present tense does this without an adverbial expression by virtue of its semantics. Namely, the current present asserts that the time of utterance is contained within the running time of the eventuality (e.g. Kamp \& Reyle 1993; $n$ denotes 'now'):

$$
\llbracket\left[\text { TP PRES }\left[\text { AspP IMP }\left[{ }_{\mathrm{vP}} \mathrm{VP}\right]\right]\right] \rrbracket=\lambda t[t=n \& \exists e(t \subseteq \operatorname{time}(e) \& \llbracket \mathrm{VP} \rrbracket(e))]
$$

The 'until when'-questions in $(7 \mathrm{~b}) /\left(20 \mathrm{~B}^{\prime}\right)$ raise a different issue than the bare whenquestions, namely one about the end point of the running time of the eventuality. Specifying one point inside the interval (the utterance time, or Nov 10, resp.) does not partially resolve this more specific issue, and hence the 'until when'-questions do not incur a violation of the Answer Ban.

\subsection{Present perfect restriction}

The present perfect restriction is reminiscent of the Present Perfect Puzzle, i.e. the incompatibility of the present perfect with so-called $\mathrm{p}$ (ositional)-specific past time adverbials (such as yesterday) in English, but not in various other languages including Dutch (see Klein 1992; Portner 2003; Pancheva \& von Stechow 2004; Rothstein 2008 among others). Rothstein's (2008: §3.5) solution to the puzzle is based on a mismatch between the present perfect's non-specific semantics and the specific semantics of p-specific adverbials. It is not clear in what way when can be seen as p-specific, so Rothstein's account cannot simply be applied to temporal questions.

I assume a PTS-based semantics for the present perfect (Iatridou, Anagnostopoulou \& Izvorski 2001; Rothstein 2008): 
When-questions and tense in Inquisitive Semantics

(22) a. The present perfect introduces an interval $t=[\mathrm{LB}, \mathrm{RB}]$ (the perfect time span, PTS), and asserts that the event time $\mathrm{E}$ is somewhere within $t$.

b. Different languages have different requirements on the relation between $\mathrm{RB}$ and the speech time $\mathrm{S}$ and reference time $\mathrm{R}$.

In English, the PTS must reach up to the speech time $(R B=R, R=S)$, whereas in Dutch and German it need not. This is based on data such as (23), whose counterparts in German and Dutch are grammatical (Rothstein 2008: 37):

(23) *I have always lived in London, but recently I moved to Amsterdam.

When the present perfect has a universal reading ("U-perfect"), the event time E occupies the entire PTS. In English this means that the right boundary of E is at the speech time. In this case a situation very similar to the current present arises: the running time interval of the event is partially specified by fixing its right boundary at the speech time, partially resolving the temporal issue by description, and as such the Answer Ban rules the question out. It is known that the universal reading only arises in combination with certain adverbial expressions (Iatridou et al. 2001), so we now have an explanation for the ungrammaticality of present perfect whenquestions such as the following:

(24) a. *When has John known Mary since 2001?

b. *When has Linda always lived in Paris?

Dutch sinds 'since' uses the present tense with stative predicates (similar to German, see Schaden 2005: 286), so there is no direct comparison of (24a) possible. The counterpart of (24b), where always forces the universal reading, is ungrammatical in Dutch too.

For existential readings, such as our book-reading example (8b), I want to draw attention to the following contrast with since-clauses (cf. Schaden 2005: 290; such cases are also discussed in work in progress by Martijn van der Klis, p.c.):

a. ?? John has read the book since February.

b. John has read the book three times since February.

c. John has known Peter since February.

As far as I know, there is no formally explicit account for the contrast between (25a) and (25b). I take the intuition to be that with eventive predicates as in (25a), an unmodified verb phrase suggests a universal reading (which is the default for statives, (25c)). Because having read the book (telic, perfective) is incompatible 
with the event going on at the speech time, (25a) is judged as infelicitous. It has been noted that adverbials such as 'three times' bring about an existential reading, and do not yield a resultant state, unlike other experiential perfects (Giannakidou 2003: 117).

Although the details need to be worked out further, I would like to claim the following for the unavailable English present perfect when-questions such as '*When has John read the book?': they normally suggest a universal reading, in parallel to (25a). We know from the discussion above that a universal perfect when-question is ruled out in English because of the Answer Ban. The question can only be rescued if it is clear that multiple answers are expected (this exception was discussed in section 2.2), which has a similar effect as iterative adverbials like 'three times' in forcing an existential reading. Under an iterative existential reading, the quantized eventualities do not overlap with the speech time, and no resultant state holds at the speech time, so there is no violation of the Answer Ban.

Finally, present perfect WHEN-questions are grammatical in Dutch (recall (9)) because the PTS in Dutch (and German) can lie fully in the past $(\mathrm{RB}<\mathrm{S})$. Hence, there is no overlap with the speech time, and the event time is not partially described, invoking no violation of the Answer Ban. As a result, we correctly predict that WHEN-questions are compatible with the present perfect in Dutch and German.

\section{Inquisitive semantics}

Temporal questions ask for time intervals, time points, or other temporal properties, and hence show that times need to be included in the ontology of a theory of question meaning. The tense restrictions discussed in the first part of this paper show furthermore that the theory should also include tense operators. Nonetheless, the major theories of question meaning that have been developed so far have mostly ignored times and tenses.

I will start by briefly looking at the one previous account known to me that analyzes temporal questions formally, Nelken \& Francez (1998). However, they explicitly underspecify the role of tense in their logical forms, as their interest is mostly in temporal NPs and PPs. The remainder of this section will be devoted to the more recent theory of Inquisitive Semantics (Ciardelli et al. 2018). The Answer Ban from section 3 played an important role in explaining tense restrictions, and was stated in terms of ISSUES. I did not provide a formal definition of 'issue' in section 3 (nor does Barker 2013), but in Inquisitive Semantics issues are precisely defined, and form the fundamental theoretical building block. Inquisitive Semantics is thus a very suitable framework to gain a better understanding of the issues raised by temporal questions, as well as making the pragmatic constraints underlying tense restrictions more precise. 
When-questions and tense in Inquisitive Semantics

\subsection{A previous account: Nelken \& Francez (1998)}

The only earlier formal semantic analysis of when-questions I am aware of is Nelken \& Francez (1998). They define an intensional language ILQ that defines a partition semantics for questions, similar in spirit to Groenendijk \& Stokhof $(1984,2011)$. Questions denote equivalence relations over worlds: they partition the set of worlds into blocks in which the same answers are true.

Below is a brief illustration of their analysis.

a. When did Mary kiss John?

(Nelken \& Francez 1998: 16)

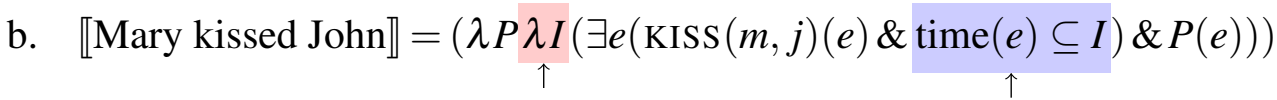
tense (placeholder)

PFV aspect

c. $\quad \llbracket$ when $\rrbracket=\lambda P \lambda I(? e[\operatorname{time}(e) \subseteq I \& P(\operatorname{time}(e))])$

d. $\llbracket$ when $\rrbracket(\llbracket$ Mary kissed John $\rrbracket)=$ $=\lambda I\left[? e\left[\operatorname{time}(e) \subseteq I \& \exists e^{\prime}\left[\operatorname{KISS}(m, j)\left(e^{\prime}\right) \& \operatorname{time}\left(e^{\prime}\right) \subseteq \operatorname{time}(e)\right]\right]\right]$

Glossing over a lot of formal details that do not matter for our purposes (see the original work for more information), I point out the following things. The representation of a declarative sentence is in (26b). Note that while perfective aspect is encoded, the anteriority of past tense is not. Instead, the LF contains a variable $I$, called the "time of interest", but is left unspecified. The idea is that $I$ is constrained by tense (p. 8), but Nelken \& Francez do not work out how this is supposed to happen. The denotation for when is given in (26c), with '? $e$ ' the interrogative operator over events $e$ (recall the debate on whether temporal questions ask for events or intervals; see the beginning of my section 3, and Nelken \& Francez 1998: 17-18). Finally, the compositional derivation of the meaning of (26a) is shown in (26d). Important here is that when combines with a full-fledged sentence that is specified for aspect (and tense, but this is left unspecified). This means that tense and aspect determine the answerhood conditions of the question, which fits with my discussion around example (14) above.

Instead of attempting to work out the details of how tense operators can be defined in terms of the parameter $I$, I will now turn to a more modern and better developed theory of the semantics of questions, Inquisitive Semantics, although I will preserve some of the insights from Nelken \& Francez.

\subsection{Implementing tense in Inquisitive Semantics}

Implementing time in semantic theory has led to a number of long-standing debates in the literature: for example on the referential vs. quantificational nature of tense, 
and on where quantification over times takes place in the grammar (e.g. Kusumoto 2005: §1, von Stechow 2009 among many others). This paper is not the place to choose sides in these complex debates, but I will assume that quantification over times exists, and that temporal anaphora also exists at a level above the sentence.

Inquisitive Semantics is a framework designed to capture the meaning of questions, by taking propositions to encode both informative and inquisitive content (Ciardelli et al. 2018). Temporal questions and tense/aspect operators have not been analyzed in the framework in detail (but see Hoeks 2017 for some first steps). My aim in this paper is not to provide a fully formalized temporal extension of Inquisitive Semantics, but rather to show what steps are involved in doing this, and what theoretical choices must be made. Since Inquisitive Semantics is a framework under active development, I will explore two approaches to implementing tense in the framework:

i. The compositional typed approach to Inquisitive Semantics (Ciardelli, Roelofsen \& Theiler 2017).

ii. Dynamic inquisitive semantics, Inq $\frac{\mathrm{D}}{\mathrm{B}}$ (Dotlačil \& Roelofsen 2019).

\subsubsection{Typed inquisitive semantics}

In a classical non-temporal framework with only types $e$ and $t$, we can add tense and aspect operators by adding times (type $i$ ) and events (type $v$ ) to the ontology:

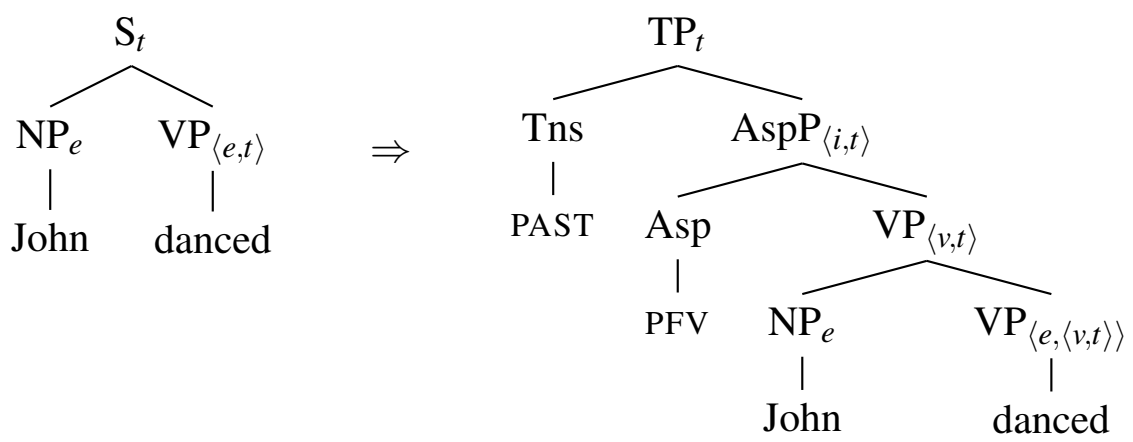

Typically, aspectual operators introduce existential quantification over events (e.g. Kratzer 1998) (I have left out worlds in (27) and (28) for simplicity, but they can be added in by following the definitions in Kratzer 1998):
a. $\llbracket \mathrm{PFV} \rrbracket=\lambda P \lambda t . \exists e(P(e) \& \tau(e) \subseteq t)$
b. $\llbracket \mathrm{IMP} \rrbracket=\lambda P \lambda t . \exists e(P(e) \& t \subseteq \tau(e))$

The tense operator anchors the time property of the event on the timeline: 
When-questions and tense in Inquisitive Semantics

$$
\llbracket \mathrm{PAST} \rrbracket=\lambda P . \exists t(t \prec n \& P(t))
$$

Ciardelli et al. (2017) present a typed, compositional version of Inquisitive Semantics. Inquisitive propositions have type $T$ (abbreviating $\langle\langle s, t\rangle, t\rangle$ ). The advantage of such a system is that we can mimic this process in (27) in inquisitive semantics:
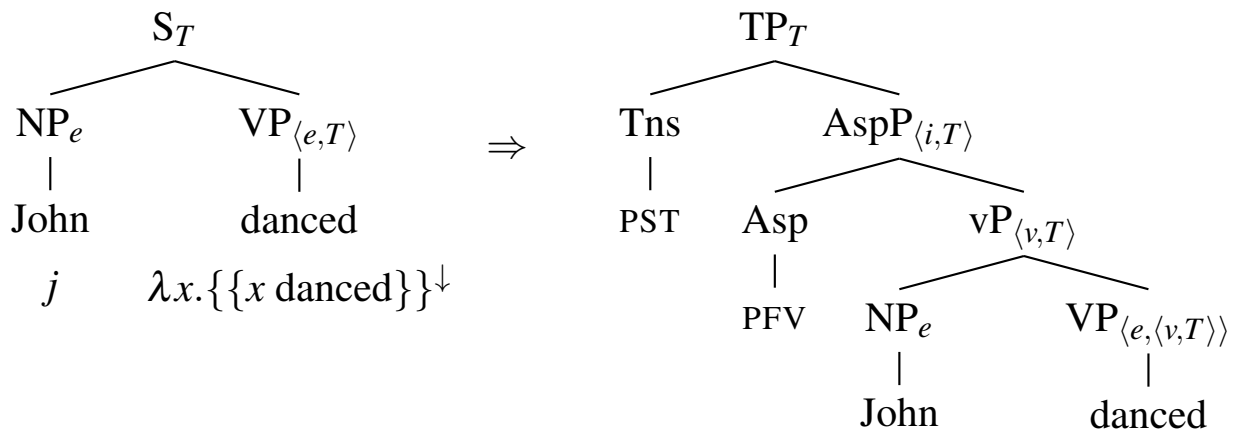

The basic idea of typed inquisitive semantics becomes clear from the tree on the left in (30): normal functional application is maintained, but the type of VP is lifted from $\langle e, t\rangle$ to $\langle e, T\rangle$ so that the denotation of the sentence will end up as an inquisitive proposition of type $T$. That sets of sets are introduced at the level of VP rather than some other level is not a significant choice (Floris Roelofsen, p.c.), but becomes relevant when functional layers for tense and aspect are added, as in the right hand tree in (30). In principle, type $T$ objects could be introduced not at VP, but higher in the tree, for instance at TP.

This also raises the question of how to define the tense and aspect operators in (30), in particular whether quantifiers over times and events should be inquisitive quantifiers or not. This rather general conceptual question has been addressed in AnderBois (2014) for events. He proposes a licensing condition for sluicing that, informally speaking, states that the antecedent should make an inquisitive contribution. A problem arises for so-called cases of SPROUTING in which no overt inquisitive content is present in the antecedent:

(31) [John baked a cake $]_{\text {antecedent, }}$, but we're all wondering [with whose help John baked ake $]_{\text {sluiced interrogative. }}$

(AnderBois 2014: 917)

AnderBois argues that existential event quantification is inquisitive, so that ' $\exists e$ (bakea-cake $(j, e)$ )' provides the required inquisitive content to license the sluice. A similar assumption would have to be made for TEMPORAL SLUICES (e.g. 'Linda left, but I don't know when'). 
Assuming that $\exists t$ and $\exists e$ are indeed inquisitive, the following definitions may be proposed for (30):

$$
\begin{aligned}
\text { a. } \quad \llbracket \mathrm{PFV} \rrbracket & \left.=\lambda P_{\langle v, T\rangle} \lambda t_{i} \cdot \bigcup_{e: \tau(e) \subseteq t} P(e) \quad \text { (type }\langle\langle v, T\rangle,\langle i, T\rangle\rangle\right) \\
& =\lambda P_{\langle v, T\rangle} \lambda t_{i \cdot}\{s \mid s \in P(e) \text { for some } e \text { such that } \tau(e) \subseteq t\} \\
\text { b. } \quad \llbracket \mathrm{PST} \rrbracket & =\lambda P_{\langle i, T\rangle} \cdot \bigcup_{t: t \prec n} P(t)
\end{aligned}
$$

$$
\llbracket \text { WHEN } \rrbracket=\lambda P_{\langle i, T\rangle} \bigcup_{t \in D_{i}} P(t)
$$

For comparison, the definition of $\llbracket$ wHO $P_{\langle e, T\rangle} \rrbracket$ is $\bigcup_{x \in D_{e}} P(x):=\{s \mid s \in P(x)$ for some $\left.x \in D_{e}\right\}$ in Ciardelli et al. (2017: 20).

Instead of working this out in further detail, I will pause here and outline two conceptual problems with this approach. The first problem is the overgeneration of inquisitive content. If tense operators (and WHEN) are inquisitive operators, every sentence becomes inquisitive, given that every sentence in English is obligatorily marked for tense. The contrast between inquisitive sentences (e.g. ones containing disjunction or indefinites), and non-inquisitive sentences is lost.

More concretely, consider a simple polar question in past tense:

\section{Did John read a book?}

This should (still) represent an issue with two alternatives, not an issue with infinitely many alternatives about all possible past times of John's book-reading.

It should be noted that this situation, in which a sentence contains more than one inquisitive operator, can also occur if tense is left out of consideration, as has been discussed in the Inquisitive Semantics literature. For example, take a disjunctive polar question, i.e. a combination of the inquisitive operations of disjunction and polar question formation. It only raises a polar question issue ([John-or-Bill comes] vs. $\neg$ [John-or-Bill comes]), as opposed to the corresponding alternative question, which has a different intonation. See (35) (ignore future tense):
a. Will John-or-Bill ${ }^{\uparrow}$ come?
[disjunctive polar question]
b. ?!(John come $\vee$ Bill come $)$
(Ciardelli et al. 2018)

Here the alternatives introduced by disjunction should not reach up to the proposition expressed by the polar question. This is achieved by means of the issuecancelling projection operator !:

$$
\begin{array}{ll}
! \phi=\mathscr{P}(\operatorname{info}(\phi)) & \text { (semantically) } \\
! \phi=\neg \neg \phi & \text { (syntactically) }
\end{array}
$$


As shown in (35b), the alternatives introduced by disjunction are closed off by ! before combining with the question operator?.

One can apply this idea in a tensed version of Inquisitive Semantics, in order to deal with problematic sentences such as the past tense question in (34):

Did John read a book? $\rightsquigarrow \quad$ ?! PST PFV (John read-book)

However, because of the syntactic nature of ! as a sentential operator, complications arise when the two inquisitive operators stand in a different scope relation:
a. Someone laughed.
b. !PST PFV someone laugh
$\Leftarrow$ suppresses all alternatives
c. someone $\lambda x$ !PST PFV $x$ laugh

(37b) (incorrectly) closes off all alternatives, including those of the indefinite. Instead, the generalized quantifier has to raise above! in order to retain its inquisitive contribution, (37c). As a general method of dealing with tense operators, the procedure of inserting !-operators at various places and applying quantifier movement lacks independent empirical motivation. It also undermines the point of having inquisitive tense operators, when their alternatives are always closed off anyway.

The second problem with the general approach outlined in this subsection concerns the relation between inquisitiveness and "raising issues". In an intuitive sense, the use of a tense operator in a simple sentence such as 'John danced' does not raise an issue of 'When did John dance?' into the discourse. This has been observed earlier by Barker (2013: 215). However, inquisitive operators have typically been considered as issue-introducing operators.

Some analysis of the (short) history of the relation between "issue raising" and the formal property of inquisitiveness in the Inquisitive Semantics literature is worthwhile. I take the original insight to be roughly the following:

"If a proposition consists of two or more possibilities, it is inquisitive: it invites the other participants to respond in a way that will lead to a cooperative choice between the proposed alternatives. In this sense, inquisitive propositions raise an issue."

(Groenendijk \& Roelofsen 2009: 3)

For example, ignorance implicatures in disjunctions and modified numerals are treated as issues raised by inquisitive propositions (Coppock \& Brochhagen 2013). Later, different perspectives have been taken on the notion of "invite" in the quote above (see e.g. Ciardelli, Groenendijk \& Roelofsen 2012: 42). More recently, the dynamic perspective on Inquisitive Semantics (more in section 4.2.2 below) has taken a different perspective: all declarative sentences, including ones with disjunction and indefinites, are made non-inquisitive by means of the ! operator. 


\subsubsection{Dynamic inquisitive semantics}

Dynamic inquisitive semantics, Inq $\mathrm{D}$ (Dotlačil \& Roelofsen 2019), brings discourse referents and anaphora to Inquisitive Semantics. It separates inquisitiveness from dynamicity, combining insights from Inquisitive Semantics and classic theories of dynamic semantics such as DPL (Groenendijk \& Stokhof 1991). Technically, an information state is now a set of world-assignment function pairs $\langle w, g\rangle$. A context is (still) a non-empty downward closed set of information states. Existential quantification is inquisitive in earlier versions of Inquisitive Semantics (I'll refer to them as $\ln q_{B}$ ), but in $\operatorname{lnq}_{B}$ it is broken down into two operations: first adding a discourse referent $x$ (written $[x]$ ), and then updating with its scope.

Someone laughs. $\rightsquigarrow !([x] ; \operatorname{laugh}\{x\})$

In Inq $_{B}^{\mathrm{D}}$ all declaratives are closed off with !, so while (38) activates a discourse referent, it does not raise an issue into the discourse: indefinites are dynamic but not inquisitive. An operator ? $x$ is introduced that "raises an issue about the identity of discourse referent $x$ ". (The construct ?x should not be confused with $? \phi$.)

$$
C[? x]=\left\{s \in C \mid \text { for all }\langle w, g\rangle,\left\langle w^{\prime}, g^{\prime}\right\rangle \in s: g(x)=g^{\prime}(x)\right\} \quad \text { (D\&R, p. 11) }
$$

Wh-questions are translated as an indefinite sentence followed by $? x:^{8}$

$$
\text { Who laughed? } \rightsquigarrow !([x] ; \operatorname{laugh}\{x\}) ; ? x
$$

In order to add tense to the system, we can add discourse referents for times and events. They are introduced in a parallel fashion to individuals $([t],[e])$.
a. 'John left'
$!([t] ;$ leave $\{j, t\})$
b. 'When did John leave?' $\rightsquigarrow \quad !([t]$; leave $\{j, t\}) ; ? t$

This makes clear the similarity between quantification over individuals and over times and events, without making everything inquisitive. A temporal discourse referent can be introduced by $[t]$, and then be picked up later in subsequent discourse, thus accounting straightforwardly for temporal anaphora:

8 Note that (40) is impressionistically very similar to sluices: first an indefinite is introduced, and then an issue is raised about its identity. However, the authors of the theory do not intend there to be any formal connection between (40) and sluices (Jakub Dotlačil, p.c.). On the other hand, a theory like AnderBois (2014), which proposes a licensing condition for sluices based on the inquisitive contribution of disjunctions and indefinites, will have to be adapted if $\ln _{\mathrm{B}}^{\mathrm{D}}$ is adopted. 
When-questions and tense in Inquisitive Semantics

$$
\mathrm{John}^{x} \text { left }^{t} . \mathrm{He}_{x} \text { went }_{t} \text { home. }
$$

It is worth noting that many (recent) works on the present perfect, and on tense and aspect generally, use a DRT framework, where in other domains of semantics this is perhaps less common. The advantage is that events and times can be introduced as discourse referents in order to explain the complicated discourse-level behavior of tense (de Swart 2007; Rothstein 2008; Nishiyama \& Koenig 2010; Kamp, Reyle \& Rossdeutscher 2015). $\operatorname{lnq}_{\mathrm{B}}^{\mathrm{D}}$ connects better to this approach in the literature, as it preserves the notion of a discourse referent.

\section{Conclusion and future work}

I proposed an account for tense restrictions in WHEN-questions based on extending pragmatic constraints on partially resolved questions to the temporal domain. The broader point, in slogan form, is that a semantic theory of questions needs to take tense seriously. Taking Inquisitive Semantics as a test case, formal implementation of tense, however, has proven to be not straightforward: the researcher faces a choice between a more classic approach (typed, compositional Inq $_{B}$ ), and a dynamic approach. The former allows a more "traditional" approach of adding functional Tense/Aspect syntactic projections, and working with the Heim \& Kratzer-style approach to the syntax-semantics interface. The dynamic approach has advantages in that in can capture temporal anaphora, and makes use of discourse referents. The formal details have been rather brief in this paper, in particular on $\operatorname{lnq}_{\mathrm{B}}^{\mathrm{D}}$ in section 4.2.2. In future work, we want to develop a fully formalized implementation of time in Inquisitive Semantics, addressing the technical challenges outlined above.

This study of temporal questions also leaves a lot of future work on the empirical side. More work is needed on other temporal questions than just WHENquestions (see the list in (1)), on non-temporal WHEN-questions (recall (10) and (11) from section 2.2), and further cross-linguistic comparison. Furthermore, there is the question of how question word when is related to complementizer when: are the present perfect restrictions (*When Mary has left, John has been happy, but fine in French and German) related? Last but certainly not least, I have restricted attention to root questions, but embedded temporal questions are important too, especially when it comes to temporal sluices. A first exploration suggests they have different tense restrictions than root questions, given these iWeb corpus examples:

a. We will let you know when it has arrived.

[iWeb]

b. Ray can not remember when he has loved her so much.

[iWeb]

This is particularly relevant given the formal similarity between root questions and embedded questions in Inquisitive Semantics. 
Tellings

\section{References}

AnderBois, Scott. 2014. The semantics of sluicing: beyond truth conditions. Language 90(4). 887-926. doi:10.1353/lan.2014.0110.

Bade, Nadine. 2016. Obligatory Presupposition Triggers in Discourse: Universität Tübingen $\mathrm{PhD}$ dissertation. doi:10.15496/publikation-10551.

Barker, Chris. 2013. Scopability and sluicing. Linguistics and Philosophy 36(3). 187-223. doi:10.1007/s 10988-013-9137-1.

Barros, Matthew. 2013. Harmonic sluicing: Which remnant/correlate pairs work and why. In Todd Snider (ed.), Proceedings of SALT 23, 295-315. LSA. doi:10.3765/salt.v23i0.2665.

Barros, Matthew. 2014. Sluicing and Identity in Ellipsis: Rutgers University PhD dissertation. doi:10.7282/T3VM49R5.

Ciardelli, Ivano, Jeroen Groenendijk \& Floris Roelofsen. 2012. Inquisitive semantics. NASSLLI lecture notes.

Ciardelli, Ivano, Jeroen Groenendijk \& Floris Roelofsen. 2018. Inquisitive semantics. Oxford University Press. doi:10.1093/oso/9780198814788.001.0001.

Ciardelli, Ivano, Floris Roelofsen \& Nadine Theiler. 2017. Composing alternatives. Linguistics and Philosophy 40. 1-36. doi:10.1007/s10988-016-9195-2.

Coppock, Elizabeth \& Thomas Brochhagen. 2013. Raising and resolving issues with scalar modifiers. Semantics and Pragmatics 6. 3:1-57. doi:10.3765/sp.6.3.

Cowper, Elizabeth. 1998. The simple present tense in English: a unified treatment. Studia Linguistica 52(1). 1-18. doi:10.1111/1467-9582.00027.

Dotlačil, Jakub \& Floris Roelofsen. 2019. Dynamic inquisitive semantics: anaphora and questions. Talk at Sinn und Bedeutung 23 and InqBnB 3.

Downing, Angela \& Philip Locke. 2006. English grammar: A university course. Routledge.

Giannakidou, Anastasia. 2003. A puzzle about until and the Present Perfect. In Artemis Alexiadou, Monika Rathert \& Arnim von Stechow (eds.), Perfect explorations, 101-133. Mouton de Gruyter. doi:10.1515/9783110902358.

Ginzburg, Jonathan. 1992. Questions, queries and facts: A semantics and pragmatics for interrogatives: Stanford University PhD dissertation.

Groenendijk, Jeroen \& Floris Roelofsen. 2009. Inquisitive semantics and pragmatics. Presented at the Stanford workshop on Language, Communication and Rational Agency, May 30-31, 2009.

Groenendijk, Jeroen \& Martin Stokhof. 1984. Studies in the Semantics of Questions and the Pragmatics of Answers: University of Amsterdam $\mathrm{PhD}$ dissertation.

Groenendijk, Jeroen \& Martin Stokhof. 1991. Dynamic predicate logic. Linguistics and Philosophy 14. 39-100. doi:10.1007/bf00628304.

Groenendijk, Jeroen \& Martin Stokhof. 2011. Questions. In Johan van Benthem \& 
When-questions and tense in Inquisitive Semantics

Alice ter Meulen (eds.), The Handbook of Logic and Linguistics, 1059-1132. Kluwer Academic Publishers. doi:10.1016/B978-0-444-53726-3.00025-6.

Han, Chung-hye \& Laura Siegel. 1997. Syntactic and semantic conditions on NPI licensing in questions. In Brian Agbayani \& Sze-Wing Tang (eds.), Proceedings of West Coast Conference in Formal Linguistics (WCCFL) 15, 177-191. CSLI Publications.

Harris, Jesse A. 2014. Who else but Sarah? In Carson Schütze \& Linnaea Stockall (eds.), Connectedness: Papers in Celebration of Sarah VanWagenen. UCLA Working Papers in Linguistics, 175-187. UCLA.

Heim, Irene \& Angelika Kratzer. 1998. Semantics in Generative Grammar. Oxford: Blackwell.

Hoeks, Morwenna. 2017. Towards a competition account of the present perfect: The case of the indefinite simple past. Internship report, Time in Translation research project.

Iatridou, Sabine, Elena Anagnostopoulou \& Roumyana Izvorski. 2001. Observations about the form and meaning of the Perfect. In Michael Kenstowicz (ed.), Ken Hale: A Life in Language, 189-238. Cambridge, MA: MIT Press.

Kamp, Hans \& Uwe Reyle. 1993. From Discourse to Logic: Introduction to ModelTheoretic Semantics of Natural Language, Formal Logic and Discourse Representation Theory. Dordrecht: Kluwer.

Kamp, Hans, Uwe Reyle \& Antje Rossdeutscher. 2015. Perfects as Feature Shifting Operators. Ms., Universität Stuttgart.

Kiss, Angelika. 2017. Meta-conversational since when-questions and the common ground. In Proceedings of SemDIAL 2017 (SaarDial) Workshop on the Semantics and Pragmatics of Dialogue, 31-40. doi:10.21437/SemDial.2017-4.

Klein, Wolfgang. 1992. The Present Perfect Puzzle. Language 68. 525-552. doi: $10.2307 / 415793$.

Koehn, Philipp. 2005. Europarl: A parallel corpus for statistical machine translation. In Machine Translation summit, vol. 5, 79-86.

Kratzer, Angelika. 1998. More Structural Analogies Between Pronouns and Tenses. In Devon Strolovitch \& Aaron Lawson (eds.), Proceedings of SALT 8, 92-110. Ithaca, NY: Cornell University. doi:10.3765/salt.v8i0.2808.

Kroll, Margaret. 2016. Polarity reversals under sluicing. In Robert Truswell, Chris Cummins, Caroline Heycock, Brian Rabern \& Hannah Rohde (eds.), Proceedings of Sinn und Bedeutung 21, 713-729.

Kusumoto, Kiyomi. 2005. On the quantification over times in natural language. Natural Language Semantics 13(4). 317-357. doi:10.1007/s11050-005-4537-6.

Nelken, Rani \& Nissim Francez. 1998. The Semantics of Temporal Questions. Technical report, Technion.

Nishiyama, Atsuko \& Jean-Pierre Koenig. 2010. What is a perfect state? Language 
86(3). 611-646. doi:10.1353/lan.2010.0014.

Pancheva, Roumyana \& Arnim von Stechow. 2004. On the Present Perfect Puzzle. In Keir Moulton \& Matthew Wolf (eds.), Proceedings of NELS 34, 469-484. GLSA Publications.

Portner, Paul. 2003. The (temporal) semantics and (modal) pragmatics of the perfect. Linguistics and Philosophy 26(4). 459-510. doi:10.1023/A:1024697112760.

van Rooy, Robert. 2003. Negative polarity items in questions: Strength as relevance. Journal of Semantics 20(3). 239-273. doi:10.1093/jos/20.3.239.

Rothstein, Björn Michael. 2008. The perfect time span. On the present perfect in German, Swedish and English. John Benjamins. doi:10.1075/la.125.

Schaden, Gerhard. 2005. On German seit - since. In Judit Gervain (ed.), Proceedings of the Tenth ESSLLI Student Session, 286-296.

von Stechow, Arnim. 2009. Tenses in compositional semantics. In Wolfgang Klein \& Ling Pi (eds.), The expression of time, 129-166. Mouton de Gruyter. doi:10.1515/9783110199031.

de Swart, Henriëtte. 2007. A cross-linguistic discourse analysis of the perfect. Journal of Pragmatics 39(12). 2273-2307. doi:10.1016/j.pragma.2006.11.006.

Theiler, Nadine. 2018. Choosing additive particles in wh-questions. Handout for talk at Sinn und Bedeutung 23.

Jos Tellings

UiL OTS, Utrecht University

Trans 10, 3512 JK Utrecht

j.1.tellings@uu.nl 